DOI: $10.5800 / G T-2021-12-3 s-0553$

\title{
FIRST RESULTS OF MAGNETOTELLURIC SOUNDINGS FOR MAPPING THE RIPHEAN SEDIMENTS OF THE BAIKAL FOREDEEP
}

\author{
A.V. Pospeev ${ }^{1}{ }^{1}$, I.K. Seminskiy ${ }^{1,2 \otimes}$, D.B. Nemtseva ${ }^{1,2}$ \\ ${ }^{1}$ Institute of the Earth's Crust, Siberian Branch of the Russian Academy of Sciences, 128 Lermontov St, Irkutsk 664033, \\ Russia \\ ${ }^{2}$ SIGMA-GEO LLC, 6 Zvezdinskaya St, Irkutsk 664039, Russia
}

ABSTRACT. The article presents the first results of magnetotelluric sounding (MTS) surveys of the Baikal foredeep. This study is part of the project of the Institute of the Earth's Crust SB RAS, which investigates the geological and geoelectrical structure of the southeastern marginal part of the Siberian platform and updates the model of the Baikal rift zone. An objective is to preliminary assess the mining potential of the Riphean strata in the Baikal foredeep. The relevance of the study centers on the possibility of discovering a new promising oil-gas field in proximity to energy-intensive industrial and agricultural enterprises. The MTS section of the sedimentary cover shows an increased conductivity of its lower part, which is most likely due to highly porous carbonate-terrigenous rocks in the middle - lower part of the 'Baikal threemember' structure. The intra-lithospheric conductive layer that hosts most of the earthquake hypocenters of the Baikal rift is investigated.

KEYWORDS: Baikal foredeep; Baikal rift; magnetotelluric sounding; hydrocarbon; Riphean; intra-lithospheric conductive layer

FUNDING: A part of this study was performed using the equipment of the Centre of Geodynamics and Geochronology, Institute of the Earth's Crust SB RAS.

\section{SHORT COMMUNICATION}

Correspondence: Igor K. Seminskiy, iks@crust.irk.ru
Received: July 29, 2021

Revised: August 27, 2021

Accepted: September 13, 2021

FOR CITATION: Pospeev A.V., Seminskiy I.K., Nemtseva D.B., 2021. First results of magnetotelluric soundings for mapping the Riphean sediments of the Baikal foredeep. Geodynamics \& Tectonophysics 12 (3s), 769-775. doi:10.5800/GT-2021-12-3s-0553 


\title{
ПЕРВЫЕ РЕЗУЛЬТАТЫ МАГНИТОТЕЛЛУРИЧЕСКИХ ЗОНДИРОВАНИЙ ПРИ КАРТИРОВАНИИ РИФЕЙСКИХ ОТЛОЖЕНИЙ ПРИБАЙКАЛЬСКОГО КРАЕВОГО ПРОГИБА
}

\author{
А.В. Поспеев ${ }^{1}$, И.К. Семинский ${ }^{1,2}$, Д.Б. Немцева ${ }^{1,2}$
}

${ }^{1}$ Институт земной коры СО РАН, 664033, Иркутск, ул. Лермонтова, 128, Россия

${ }^{2} 000$ «СИГМА-ГЕО», 664039, Иркутск, ул. Звездинская, 6, Россия

\begin{abstract}
АНнОТАЦИЯ. В статье представлены первые результаты работ методом магнитотеллурического зондирования на территории Прибайкальского краевого прогиба, являющихся частью масштабного проекта Института земной коры СО РАН по уточнению геологического строения юго-восточной краевой части Сибирской платформы и физико-геологической модели Байкальской рифтовой зоны. Задачей настоящей работы является предварительная оценка перспективности рифейских толщ в Прибайкальском краевом прогибе. Актуальность этих исследований связана с возможностью выделения здесь новой перспективной нефтегазоносной области, находящейся в достаточной близости от крупных промышленных и сельскохозяйственных потребителей. В ходе исследований в разрезе осадочного чехла установлена повышенная проводимость его нижней части, наиболее вероятно связанная с наличием высокопористых карбонатно-терригенных пород средней - нижней части «байкальского трехчлена». Изучено поведение литосферного проводящего слоя, в диапазоне глубин залегания которого локализуется большая часть гипоцентров землетрясений на Байкальском рифте.
\end{abstract}

КЛЮЧЕВЫЕ СЛОВА: Прибайкальский краевой прогиб; Байкальский рифт; магнитотеллурическое зондирование; углеводороды; рифей; внутрилитосферный проводящий слой

ФИНАНСИРОВАНИЕ: В работе частично задействовалось оборудование ЦКП «Геодинамика и геохронология» ИнститУта земной коры СО РАН.

\section{1. ВВЕДЕНИЕ}

В западной части Сибирской платформы рифейские отложения содержат крупнейшие резервуары углеводородного сырья. Суммарные разведанные запасы нефти и газа в рифейских отложениях Юрубчено-Тохомского, Куюмбинского месторождений (Камовский свод) превышают 1 млрд т [Kontorovich et al., 1988]. В отличие от этого на юге и востоке Сибирской платформы на территории Иркутской области и Республики Саха (Якутия) рифейский этаж нефтегазоносности практически не разведан. Несмотря на то что в естественных обнажениях западного побережья Байкала известны строматолитовые известняки улунтуйской свиты так называемого байкальского трехчлена, долгое время породы рифейского возраста относились к фундаменту платформы. Поводом к этому служили результаты испытаний пород верхов верхнего рифея, вскрытых некоторыми буровыми скважинами в Иркутской области и сложенных преимущественно слабопроницаемыми аргиллитами и алевролитами.

Между тем существенное замедление прироста запасов углеводородов в породах терригенного венда, а также карбонатах венд-кембрия, наблюдаемое практически все последнее десятилетие на территории юга Сибирской платформы, побуждает обратить серьезное внимание на ее краевые части - Присаянский, Предпатомский и Прибайкальский прогибы. В целом краевые части платформ играют существенную роль в локализации углеводородов, где до настоящего времени сохраняются перспективы открытия крупных и гигантских месторождений нефти и газа. Это подтверждает опыт изучения арктического склона Аляски, Верхнеамазонского, Оринокского и других аналогичных бассейнов мира [Hunt, 1982].

Высокий потенциал Прибайкальского прогиба обусловлен существованием здесь достаточно мощных рифейских толщ, как обнажающихся на дневной поверхности, так и вскрытых колонковым и глубоким бурением [Pospeev et al., 2018]. При этом существенная сложность заключается в целом ряде факторов. Первый из них - значительное влияние на строение Прибайкальского прогиба процессов рифтогенеза. Зарождение и развитие Байкальского рифта сильно повлияло на тектонику краевой части Сибирской платформы в целом [Seminsky et al., 2013]. Отложения юго-восточного борта рифейского прогиба в силу наличия значительных напряжений сжатия - сдвига оказались смяты в многочисленные складки и разбиты разломами. Существует высокая вероятность того, что часть из них погребена под кайнозойскими осадками Байкальской впадины. На это косвенно указывает наличие нефтепроявлений на дне озера, открытых в 2009 г. при погружении глубоководных обитаемых аппаратов «Мир» [Bogdanov, Sagalevich, 2002].

Следующая проблема - выявление характера выклинивания карбонатных и терригенно-карбонатных пород улунтуйской и голоустенской свит под венд-кембрийскими отложениями, поскольку северо-западный фланг рифейского прогиба нигде не вскрыт бурением на полную мощность и не изучен достаточно сейсмическими и электромагнитными зондированиями. Поскольку рифейские отложения практически всеми 
исследователями расцениваются как нефтегазоматеринские, а вышележащие более молодые венд-кембрийские породы включают солеродные пласты, здесь могут существовать условия формирования крупных скоплений нефти и газа.

Отличительной особенностью территориального положения южной части Прибайкальского регионального прогиба является его близость к Иркутско-Черемховскому промышленному узлу и наиболее развитым сельскохозяйственным зонам Усть-Ордынского округа. Это определяет логистические преимущества и обеспечивает ускоренные темпы освоения. Понятно, что решение столь сложной проблемы, как изучение новой нефтегазоносной области, требует выполнения соответствующего объема региональных геолого-геофизических исследований, а также параметрического бурения [Shemin et al., 2018]. Построение геологической модели Прибайкальского прогиба даст возможность выделить здесь наиболее интересные геологические объекты, достойные проведения поисковых геологоразведочных работ.

\section{2. МЕТОД ИССЛЕДОВАНИЯ}

С учетом аргументов, изложенных выше, было принято решение попытаться получить информацию о строении юго-восточной части Прибайкальского прогиба методом магнитотеллурического зондирования (MT3), ввиду простоты его производства и большой глубинности исследований. При этом решались две геологические задачи - собственно изучение строения пород осадочного чехла и кристаллического фундамента, а также исследование геоэлектрического строения земной коры и верхней мантии.

Что касается территории Байкальской рифтовой зоны в целом, то единичные МТЗ производились здесь с 60-х гг. прошлого века [Gornostaev et al., 1970]. Hесмотря на рекогносцировочный характер работ (шаг между наблюдениями 40-60 км), использование аналогового способа регистрации и обработки данных, удалось получить общие представления о характере глубинного геоэлектрического разреза, которые имеют важное научное значение по сей день.

В дальнейшем комплексные глубинные электромагнитные исследования проводились в зоне строительства трассы БАМа (1976-1982 гг.) [Puzyrev, Mandelbaum, 1984], в южном Прибайкалье и Забайкалье [Popov et al., 1988; Kuzminykh, 1994]. Изученность региона глубинной электроразведкой, производимой современными цифровыми станциями, крайне скудна и спорадична. В частности, это точечные зондирования становлением поля в ближней зоне в Приольхонье [Kozhevnikov, 1998] и два профиля МТЗ в центральной части рифтовой зоны [Moroz Yu.F., Moroz T.A., 2012; Seminsky et al., 2013].

Этими работами изучены выклинивание осадочной толщи юго-восточного фланга Сибирской платформы и поведение внутрилитосферного проводящего слоя и астеносферы. Несмотря на высокую научную значимость полученных геологических результатов, сложилась парадоксальная ситуация, связанная с тем, что общий объем проведенных исследований крайне мал и совершенно недостаточен для решения многих геологических вопросов как строения краевой части платформы, так и глубинного геоэлектрического строения северо-запада Байкальского рифта. Одна из самых интересных геологических провинций России, которая многие годы являлась опытным полигоном отечественной геоэлектрики, до сих пор не обеспечена достаточно надежной геоэлектрической моделью, сформированной с использованием современных возможностей электромагнитных зондирований. Вместе с тем именно геоэлектрические данные позволяют в значительной степени снизить круг неопределенности в истолковании геологической природы наблюдаемых особенностей глубинной физико-геологической модели Байкальского рифта, в том числе ее термического и флюидного режимов.

\section{3. РЕЗУЛЬТАТЫ ПЕРВЫХ ИССЛЕДОВАНИЙ}

На основании вышесказанного актуальность проведения новых глубинных электромагнитных исследований юга и юго-востока Иркутского амфитеатра, первые результаты которых освещены в настоящей статье, очевидна.

Предпосылкой успеха решения поставленных задач является контрастность геоэлектрических свойств геологических объектов, обусловленная различием их минерального состава, но главным образом объема и свойств проводящих включений. Для безрудных и безглинистых пород основным фактором, формирующим уровень удельного электрического сопротивления (УЭС), является система проводящих трещиннопоровых каналов, заполненных водными растворами. Поскольку пористость кристаллических горных пород, как правило, очень мала, их удельное сопротивление в большинстве случаев превышает многие сотни Ом·м. В осадочных горных породах, не подвергнутых значительной литификации, трещинно-поровые растворы, содержащиеся в породе, даже в количестве первых процентов, значительно понижают их УЭС. Количественная связь коэффициента пористости и удельного сопротивления обычно описывается известной формулой Арчи [Dakhnov, 1985]. При этом УЭС собственно порового флюида достаточно просто оценивается в соответствии с его минерализацией и температурой [Kobranova, 1986]. Для диапазона флюидонасыщенной пористости от первых десятых долей до 10 и более процентов удельное электрическое сопротивление рифейских отложений может составлять от 10 до 200 Ом·м, причем плотные литифицированные аргиллит-алевролитовые породы качергатской свиты более высокоомны, а УЭС подстилающих их терригеннокарбонатных пород улунтуйской и голоустенской свит значительно ниже. Это обусловлено их повышенной пористостью и флюидонасыщенностью.

Исследования МТЗ производились по профилю, перпендикулярному простиранию Байкальской впадины 
Стратифицированные образования

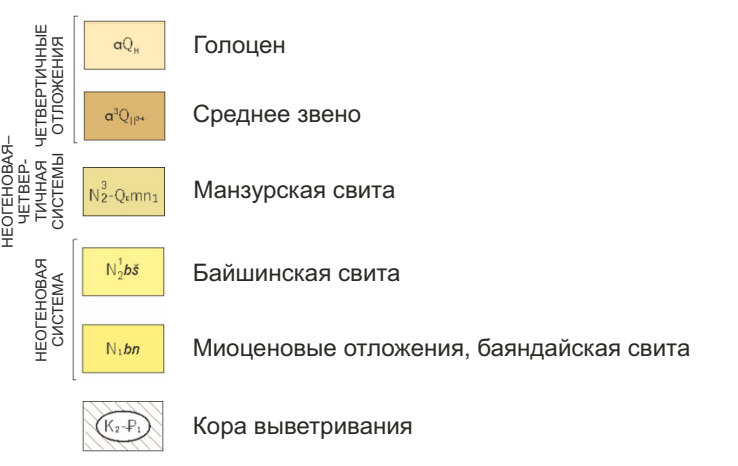

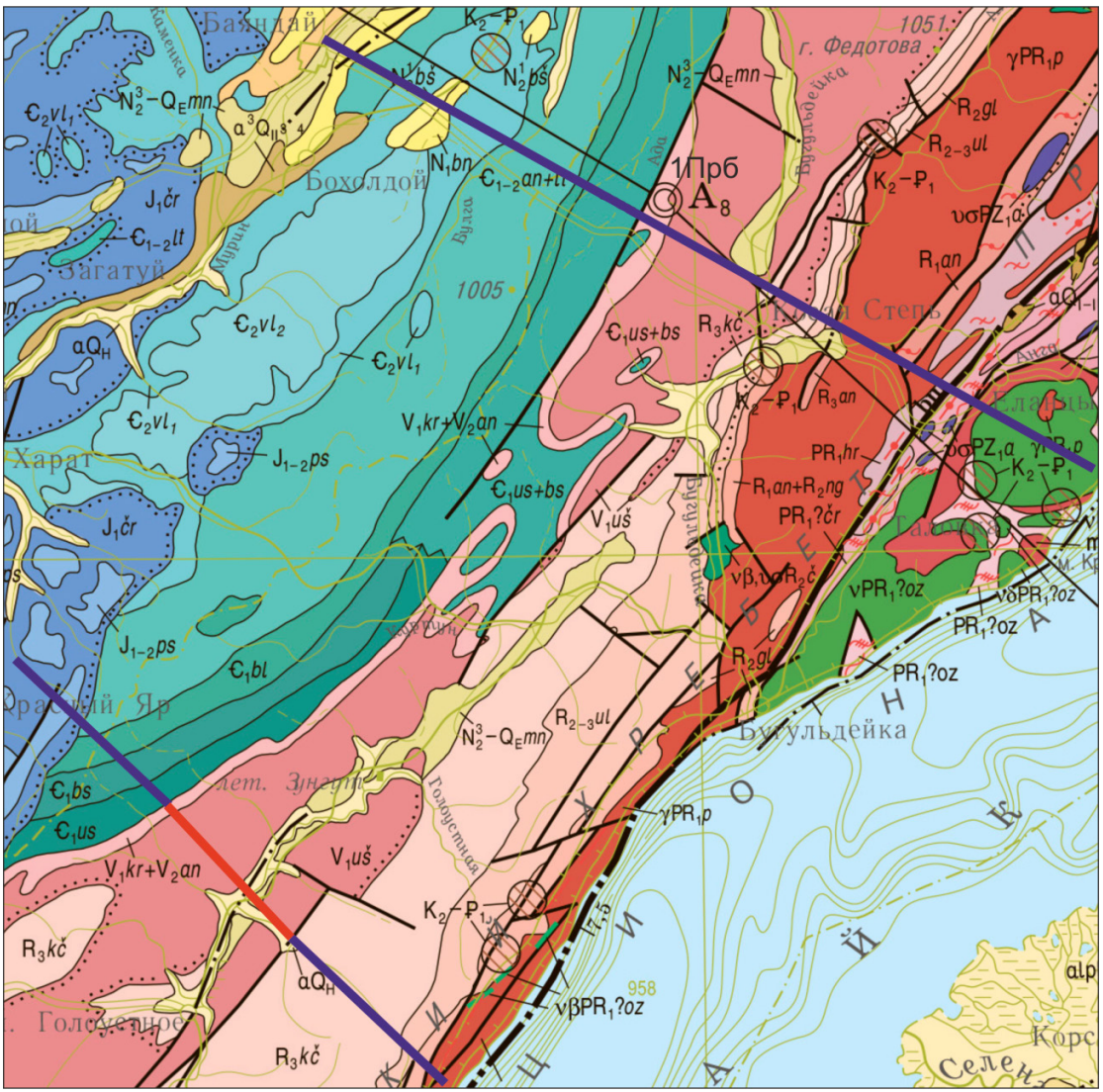

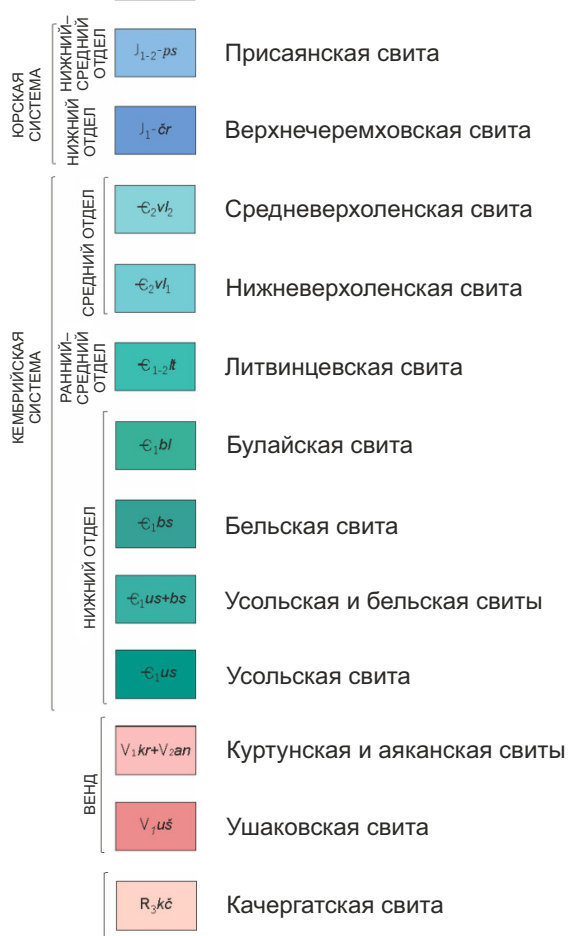

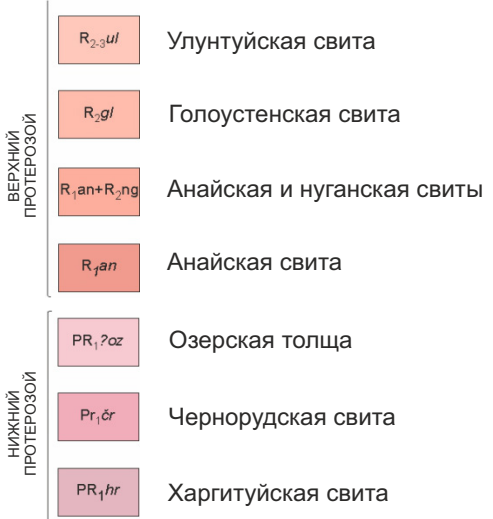

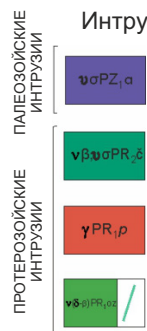

Интрузивные образования

v॰PZ,

Чайский комплекс

Приморский комплекс

vsom a / Озерский комплекс, первая фаза

Прочие знаки

——. Границы между разновозрастными геологическими образованиями: a - согласного залегания, б - несогласного

Главные доложивущие разломы: а - выходящие на поверхность, б - скрытые под перекрывающими образованиями Прочие разломы, преимущественно неустановленной морфологии: а - выходящие на поверхность морфологии: а - выходящие на поверхность,

Фации регионального метаморфизма: а - зеленосланцевая б - эпидот-амфиболитовая, в - амфиболитовая, г - гранулитовая Мел-палеогеновая кора выветривания, не выражающаяся в масштабе карты

\begin{tabular}{|c|c|c|c|c|}
\hline идросеть & & $\begin{array}{l}\text { Проектируемые } \\
\text { профили МТ3 }\end{array}$ & 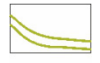 & Дорога \\
\hline MT3 & $0^{1 П p 6}$ & Скважина & & Надвиги \\
\hline
\end{tabular}

Рис. 1. Схема расположения профилей МТЗ на фрагменте геологической карты (по [State Geological Мap..., 2006] с изменениями)

Fig. 1. MTS profiles in a fragment of the geological map (after [State Geological Map..., 2006], incl. amendments). 
(ориентировка: северо-запад - юго-восток). Пространственно он расположен несколько юго-западнее линии геологического разреза, приведенного на цифровом листе геологической карты N-48, составленной ФГУП «ВСЕГЕИ» [State Geological Map..., 2006]. Поскольку находящаяся на линии геологического разреза скважина «1-Прибайкальская» из рифейских отложений вскрыла только верхнюю часть качергатской свиты, а геофизические данные по этому направлению отсутствуют, поведение рифея на разрезе является в большей степени геологическим прогнозом, чем результатом интерпретации фактического материала (рис. 1).

При производстве полевых работ использовались канадские цифровые станции Phoenix Geophysics MTU-5A; регистрировались четыре компоненты электромагнитного поля Земли $(E x, E y, H x, H y)$ на точках с шагом 2 км. Обработка полученных материалов проводилась с помощью программ SSMT-2000 (Phoenix Geophysics) и ЕПИ-КИТ (000 «Северо-Запад»).

Инверсия полученных данных выполнялась в программном комплексе LineInterMT (разработка А.В. Поспеева). В основу логики комплекса положен принцип выбора квазипродольных по отношению к геоэлектрическим неоднородностям кривых МТЗ, причем дополнительная коррекция их гальванических влияний производится путем нормализации полиномом заданного порядка. Инверсия кривых осуществляется в одномерном варианте, а для уточнения региональных
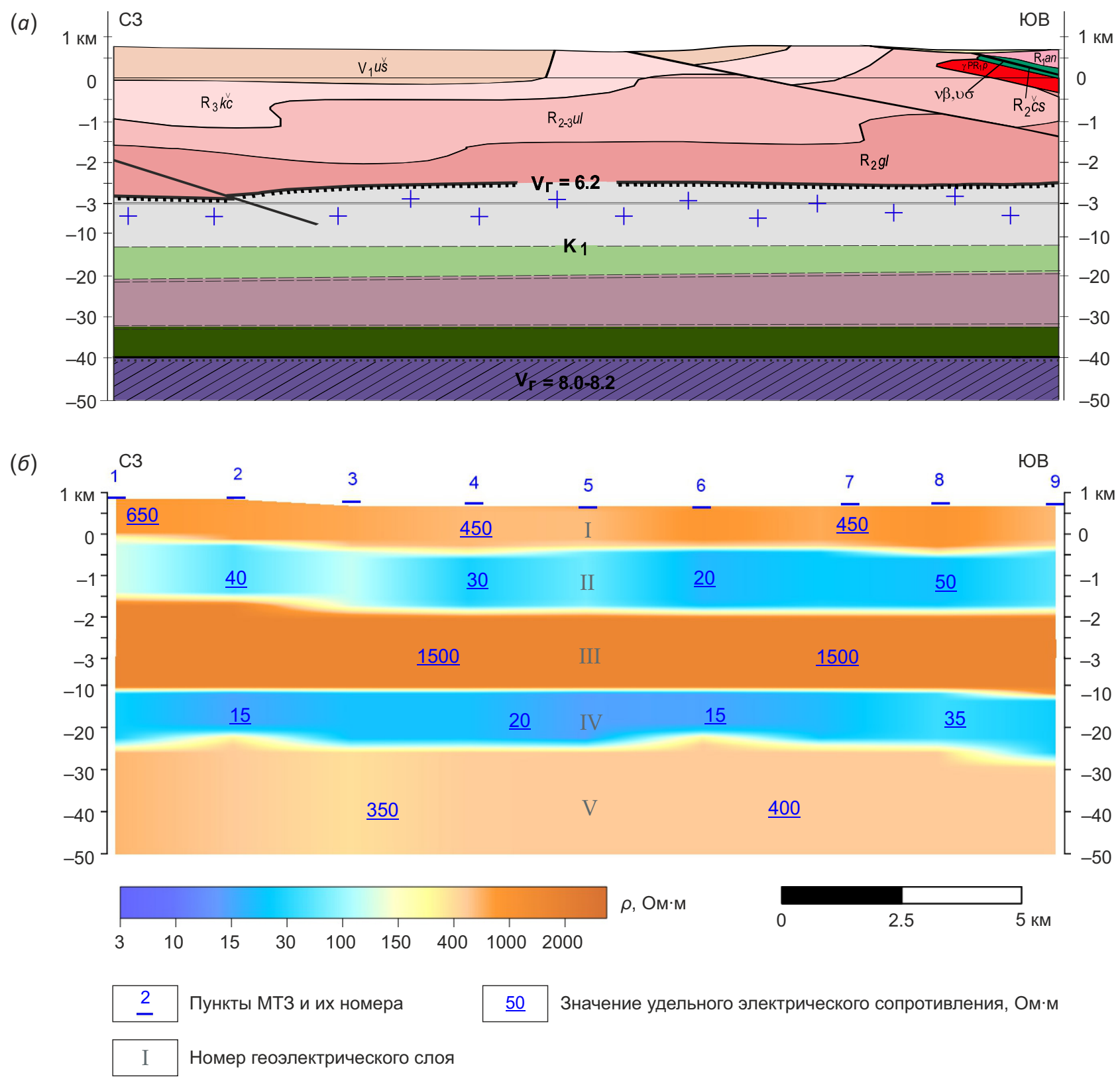

Рис. 2. Геологический (a) и геоэлектрический (б) разрезы территории исследования (по [State Geological Map..., 2006] с изменениями).

Fig. 2. Geological (a) and geoelectrical (б) sections of the study area (after [State Geological Map..., 2006], incl. amendments). 
влияний неоднородностей используется программа 2D-моделирования И.Л. Варданянц [Vardanyants, 1978a, 1978b].

Несмотря на то что к настоящему времени выполнено всего девять зондирований, получены интересные и важные в геологическом и научном отношении результаты. По результатам интерпретации магнитотеллурических данных построен геоэлектрический разрез до глубины 50 км, представленный на рис. 2.

На разрезе отчетливо выделяется осадочный чехол (слои I и II) и кристаллический фундамент (слой III), включающий проводящий слой (слой IV). Верхняя часть осадков, соответствующая аргиллит-алевролитовым отложениям ушаковской свиты венда и качергатской свиты верхнего рифея, является высокоомной (слой I). Залегающий ниже по разрезу геоэлектрический горизонт характеризуется намного более низкими значениями УЭС - 20-50 Ом'м, что позволяет его отождествить с карбонатно-терригенными отложениями улунтуйской и голоустенской свит. Следует, что их возрастные аналоги, изученные в Курейской синеклизе на профиле «Батолит» [Pashevin et al., 2008], характеризуются близкими геоэлектрическими характеристиками. Толщина проводящих рифейских отложений на рассматриваемом отрезке варьирует от 1.2 до 1.5 км, а общая толщина осадочного чехла превышает 2.5 км (слой II). Отмечается погружение кристаллического фундамента платформы в юго-восточном направлении, что свидетельствует о реальности существования Прибайкальского прогиба (слой III).

УЭС кристаллических горных пород, залегающих ниже кристаллического фундамента, составляет около 350 Ом•м. На глубине 12.5-13.0 км отмечается проводящий слой толщиной около 15 км, в пределах которого УЭС понижается до 30-40 Ом•м (слой IV). Следуя [Pospeev et al., 1981], будем называть его «литосферным», поскольку в зависимости от регионального термического и флюидного режимов он может находиться как в пределах средней - нижней коры, так и в верхах верхней мантии [Pospeev, 2004].

В пределах Байкальской рифтовой системы большинство гипоцентров землетрясений сосредоточено в том же диапазоне глубин, что и литосферный слой, что косвенно позволяет считать его сейсмогенерирующим. С этой точки зрения может иметь перспективы мониторинг его параметров в связи с процессами подготовки и разрядки землетрясений.

\section{4. ВЫводы}

В результате работ МТЗ на территории Прибайкальского краевого прогиба, являвшихся небольшой частью масштабного проекта по уточнению физико-геологической модели Байкальской рифтовой зоны, были получены весьма интересные с геологической точки зрения данные.

Подтверждено наличие Прибайкальского прогиба по кровле кристаллического фундамента. В осадочном чехле выделены высокоомная часть, соответствующая нижнему венду и верхней свите «байкальского трехчлена», а также подстилающий проводящий горизонт, приуроченный, вероятнее всего, к отложениям улунтуйской и голоустенской свит.

Уровень удельного электрического сопротивления карбонатно-терригенных осадков, залегающих на кристаллическом фундаменте, позволяет говорить о наличии здесь высокопористых образований, аналогичных зонам коллекторов одновозрастных отложений Курейской синеклизы.

Положение литосферного проводящего слоя на изученной части Прибайкальского прогиба позволяет говорить о ее приуроченности к активной части периферии Байкальского рифта

\section{REFERENCES / ЛИТЕРАТУРА}

Bogdanov Yu.A., Sagalevich A.M., 2002. Geological Studies from Deep-Sea Manned Vehicles Mir. Nauchny Mir, Moscow, 320 p. (in Russian) [Богданов Ю.А., Сагалевич А.М. Геологические исследования с глубоководных обитаемых аппаратов «Мир». М.: Научный мир, 2002. 320 с.].

Dakhnov V.N., 1985. Geophysical Methods for Determining Reservoir Properties and Oil and Gas Contents of Rocks. Nedra, Moscow, 310 p. (in Russian) [Дахнов В.Н. Геофизические методы определения коллекторских свойств и нефтегазонасыщения горных пород. М.: Недра, 1985. 310 c.].

Gornostaev V.P., Mikhalevsky V.I., Pospeev V.I., 1970. Deep Magnetotelluric Sounding in the Southern Part of the Siberian Platform and the Baikal Rift Zone. Russian Geology and Geophysics 4, 111-117 (in Russian) [Горностаев В.П., Михалевский В.И., Поспеев В.И. Глубинные магнитотеллурические зондирования на юге Сибирской платформы и в зоне Байкальского рифта // Геология и геофизика. 1970. Т. 4. С. 111-117].

Hunt J., 1982. Petroleum Geochemistry and Geology. Mir, Moscow, 706 p. (in Russian) [Хант Дж. Геохимия и геология нефти и газа. М.: Мир, 1982. 706 с.].

Kobranova V.N., 1986. Petrophysics. Textbook for Universities. Nedra, Moscow, 392 p. (in Russian) [Кобранова В.Н. Петрофизика: Учебник для вузов. М.: Недра, 1986. 392 c.].

Kontorovich A.E., Kontorovich A.A., Krinin V.A. et al., 1988. The Yurubchen-Tokhoma Oil and Gas Accumulation ZoneImportant Object of Concentration of Regional Works and Prospecting and Exploration in the Upper Proterozoic OilGas Province. Russian Geology and Geophysics 11, 45-95 (in Russian) [Конторович А.Э., Конторович А.А., Кринин В.А. и др. Юрубчёно-Тохомская зона нефтегазонакопления важный объект концентрации региональных и поисково-разведочных работ в верхнем протерозое нефтегазоносной провинции // Геология и геофизика. 1988. № 11. C. 45-95].

Kozhevnikov N.O., 1998. Some Features of the Structure of the Olkhon Region from Electrical Prospecting Data (Western Pribaikalie). Russian Geology and Geophysics 39 (2), 271-276 (in Russian) [Кожевников Н.О. Некоторые особенности структуры Приольхонья по данным электроразведки 
(Западное Прибайкалье) // Геология и геофизика. 1998. T. 39. №. 2. C. 271-276].

Kuzminykh Yu.V., 1994. Deep Geoelectric Structure of South Transbaikalia from Magnetotelluric Sounding Data. PhD Thesis (Candidate of Geology and Mineralogy). Irkutsk, 175 p. (in Russian) [Кузьминых Ю.В. Глубинное геоэлектрическое строение Южного Забайкалья по данным магнитотеллурических зондирований: Дис. ... канд. геол.мин. наук. Иркутск, 1994. 175 с.].

Moroz Yu.F., Moroz T.A., 2012. Deep Geoelectrical Section of the Baikal Rift. Bulletin of Kamchatka Regional Association "Educational-Scientific Center". Earth Sciences 2, 114-126 (in Russian) [Мороз Ю.Ф., Мороз Т.А. Глубинный геоэлектрический разрез Байкальского рифта // Вестник КРАУНЦ. Серия: Науки о Земле. 2012. № 2. C. 114-126].

Pashevin A.M., Tupitsyn V.A., Gomulsky V.V., 2008. Results of Magnetotelluric Studies at the Batolit Profile (Southern Part of the Siberian Platform). Journal of Mining Institute 176, 150-153 (in Russian) [Пашевин А.М, Тупицын B.A., Гомульский В.В. Результаты магнитотеллурических исследований на профиле «Батолит» (юг Сибирской платформы) // Записки Горного института. 2008. Т. 176. C. 150-153].

Popov A.M., Potapov A.S., Kuzminykh Yu.V., Baduev A.B., Parkhomov V.A., 1988. Long-Period MT Soundings in Pribaikalie. Bulletin of the USSR Academy of Sciences. Physics of the Earth 11, 83-87 (in Russian) [Попов A.М., Потапов A.C., Кузьминых Ю.В., Бадуев А.Б., Пархомов В.А. Длиннопериодные МТ-зондирования в Прибайкалье // Известия АН СССР. Физика Земли. 1988. № 11. С. 83-87].

Pospeev A.V., 2004. Geological Aspects of the Geoelectrics of the Earth's Upper Lithosphere. Russian Geophysics 4, 35- 38 (in Russian) [Поспеев А.В. Геологические аспекты геоэлектрики верхней литосферы Земли // Геофизика. 2004. № 4. С. 35-38].

Pospeev A.V., Buddo I.V., Agafonov Yu.A., Sharlov M.V., Kompaniets S.V., Tokareva O.V., Misyurkeeva N.V., Gomulsky V.V. et al., 2018. Modern Practical Electrical Prospecting. GEO, Novosibirsk, 231 p. (in Russian) [Поспеев A.В., Буддо И.В., Агафонов Ю.А., Шарлов М.В., Компаниец С.В., Токарева О.В., Мисюркеева Н.В., Гомульский В.В. и др. Современная практическая электроразведка. Новосибирск: Гео, 2018. 231 с.].

Pospeev V.I., Mikhalevsky V.I., Nikulin V.I., Ipatiev S.N., 1981. Relationship between Metallogeny of the Siberian Platform and Features of Tectonics, Magmatism, Structure and Physical State of the Earth's Crust and Upper Mantle. In: Metallogeny of the Precambrian. Abstracts of the II AllUnion Meeting on Metallogeny of the Precambrian (September 01-30, 1981). IEC SB RAS, Irkutsk, 79-80 (in Russian) [Поспеев В.И., Михалевский В.И., Никулин В.И., Ипатьев С.Н. Связь металлогении Сибирской платформы с особенностями тектоники, магматизма, строения и физического состояния земной коры и верхней мантии // Металлогения докембрия: Тезисы докладов II всесоюзного совещания по металлогении докембрия
(01-30 сентября 1981 г.). Иркутск: ИЗК СО РАН, 1981. C. 79-80].

Puzyrev N.N., Mandelbaum M.M. (Eds), 1984. Geology and Seismicity of the BAM Zone (from Baikal to Tynda). Deep Structure. Nauka, Novosibirsk, 174 p. (in Russian) [Геология и сейсмичность зоны БАМ (от Байкала до Тынды). Глубинное строение / Ред. Н.Н. Пузырев, М.М. Мандельбаум. Новосибирск: Наука, 1984. 174 с.].

Seminsky K.Zh., Kozhevnikov N.O., Cheremnykh A.V., Pospeeva E.V., Bobrov A.A., Olenchenko V.V., Tugarina M.A., Potapov V.V. et al., 2013. Interblock Zones in the Crust of the Southern Regions of East Siberia: Tectonophysical Interpretation of Geological and Geophysical Data. Geodynamics \& Tectonophysic 4 (3), 203-278 (in Russian) [Ceминский К.Ж., Кожевников Н.О., Черемных А.С., Поспеева Е.В., Бобров А.А., Оленченко В.В., Тугарина М.А., Потапов В.В. и др. Межблоковые зоны в земной коре юга Восточной Сибири: тектонофизическая интерпретация геолого-геофизических данных // Геодинамика и тектонофизика. 2013. Т. 4. № 3. С. 203-278]. https:// doi.org/10.5800/GT-2013-4-3-0099.

Shemin G.G., Migursky A.V., Smirnov M.Yu., Vakhromeev A.G., Pospeev A.V., 2018. Complex Characteristics and Quantitative Assessment of the Prospects for Oil-Gas Potential of Regional Oil-Gas Reservoirs of the Upper VendianLower Cambrian Allochthonous Carbonate Macrocomplex of the Predpatom Regional Trough (Siberian Platform). Geology and Mineral Resources of Siberia 1, 32-55 (in Russian) [Шемин Г.Г., Мигурский А.В., Смирнов М.Ю., Вахромеев А.Г., Поспеев А.В. Комплексная характеристика и количественная оценка перспектив нефтегазоносности региональных резервуаров нефти и газа верхневендсконижнекембрийского аллохтонного карбонатного макрокомплекса Предпатомского регионального прогиба (Сибирская платформа) // Геология и минеральносырьевые ресурсы Сибири. 2018. №. 1. С. 32-55].

State Geological Map of the Russian Federation, 2006. Series Angara-Yenisei. Scale 1:1000000 (Third Generation). Sheet N-48 (Irkutsk). VSEGEI Publishing House, Saint Petersburg (in Russian) [Государственная геологическая карта Российской Федерации. Серия Ангаро-Енисейская. Масштаб 1:1000000 (третье поколение). Лист N-48 (Иркутск). СПб.: ВСЕГЕИ, 2006].

Vardanyants I.L., 1978a. Calculations by the Method of Grids of Magnetotelluric Fields over Two-Dimensional Inhomogeneous Media. Part 1. Problems of Geophysics 27, 36-40 (in Russian) [Варданянц И.Л. Расчеты методом сеток магнитотеллурических полей над двумерно-неоднородными средами. Ч. 1. // Вопросы геофизики. 1978. Вып. 27. С. 36-40].

Vardanyants I.L., 1978b. Calculations by the Method of Grids of Magnetotelluric Fields over Two-Dimensional Inhomogeneous Media. Part 2. Problems of Geophysics 28, 155-163 (in Russian) [Варданянц И.Л. Расчеты методом сеток магнитотеллурических полей над двумерно-неоднородными средами Ч. 2. // Вопросы геофизики. 1978. Вып 28. С. 155-163]. 